\author{
Анастасия ОщеПковА \\ Университет имени Адама Мицкевича в Познани (Познань, Польша)
}

\title{
Концепт Я-ЖЕНЩИНА: стилистически сниженная лексика в романе Марии Арбатовой «Меня зовут женщина»
}

Целью настоящей статьи является изучение концепта Я-ЖЕНЩИНА на основе романа Марии Арбатовой «Меня зовут женщина». Поставленную перед нами задачу мы намерены решить посредством описания и анализа стилистически сниженной лексики, входящей в состав текста вышеуказанного произведения. Ещё одним существенным пунктом нашей работы является попытка перевода интересующей нас лексики на польский язык.

Данная статья состоит из трёх частей. Первая - теоретическая часть, которая приводится с целью введения читателя в тематику затрагиваемой проблемы, а также для ознакомления его с терминологией, использованной в работе. Вторая часть работы - практическая; включает в себя непосредственное описание, анализ, классификацию сниженной лексики, список предлагаемых аналогов лексических единиц (транслатем) на польском языке. В третьей части статьи мы описываем и анализируем интересующий нас концепт, а также делаем основополагающие выводы.

\section{Художественный концепт. Стилистически сниженная лексика}

Данная работа относится к области лингвокультурологии и затрагивает область когнитивной лингвистики - направления в языкознании, исследующего проблемы соотношения языка и сознания, роль языка в категоризации мира и обобщение человеческого опыта (Дзюба 2011: 3). Понятие концепт является основным понятием когнитивной лингвистики и представляет для нас особый интерес. Из имеющихся определений концепта нами выбрано определение В. А. Масловой, по мнению которой:

(...) концепт - это семантическое образование, отмеченное лингвокультурной спецификой и тем или иным образом характеризующее носителей определенной этнокультуры. Отражая этническое мировидение, концепт маркирует 
этническую, языковую картину мира. Концепт не непосредственно возникает из значения слова, а является результатом столкновения словарного значения слова с личным и народным опытом человека. Он окружен эмоциональным, экспрессивным, оценочным ореолом (Маслова 2007: 24).

Изучение концептов - важная область современной лингвистики, открывающая новые возможности в изучении языка и приносящая неоднозначные результаты. В нашей работе мы занимаемся изучением и анализом концепта Я-ЖЕНЩИНА на основе текста романа российской писательницы Марии Арбатовой «Меня зовут женщина». Роман - это художественное произведения. В связи с этим можно предположить, что интересующий нас концепт является особым типом концепта - художественным.

Так называемые художественные концепты (Гачев 1972; Зусман 2001; Миллер 2000) отражают уникальную систему представлений автора текста о мире и носят индивидуальный характер. По словам академика Лихачёва, несмотря на индивидуальный характер художественных концептов, их авторы - писатели и поэты - активно участвуют в построении и формировании общей концептосферы национального языка (Лихачев 1997: 12).

Сфера изучения художественных концептов является одной из наиболее значимых, так как именно такие концепты являются общедоступными и способны серьёзно влиять на сознание всего народа посредством художественной литературы, которая, в свою очередь, значительно влияет на формирование менталитета нации.

Любой концепт изучается лингвистами через слово: «(..) за каждым именем - знаком - словом стоит концепт» (Адамова 2011). Учёные, занимающиеся изучением концептов (Стернин 2006, Зусман 2001, Попова 2007 , Карасик 2004), рассматривают художественное произведение как систему знаков - текст, который отражает сознание автора, т.е. все те проблемы действительности, которые актуальны именно для этой личности.

Для описания концепта Я-ЖЕНЩИНА мы выделили из текста лексику, связанную с темой женщины, проанализировав ту часть данной лексики, которая содержит стилистически сниженные лексические единицы. В дальнейшем этот анализ обеспечит нам более точное описание негативно окрашенной области концепта Я-ЖЕНЩИНА. В связи с этим следует приблизиться к дефиниции интересующего нас понятия. По данным «Словаря лингвистических терминов», так называемая сниженная лексика делится на два разряда: разговорная лексика, просторечная лексика (см.: Жеребило 2010: 84).

Разговорная лексика употребляется в непринужденной речи, может содержать как положительную, так и отрицательную оценку. Просторечная лексика употребляется в эмоциональных речевых ситуациях, при дружеских и фамильярных отношениях. Разговорная и просторечная лексика находят- 
ся в пределах литературного словаря (см.: Жеребило 2010: 84). Для нас же особый интерес представляет стилистически сниженная лексика, выражающая неодобрительную (т.е. зачастую именно пейоративно окрашенную) оценку. В словарях пейоративную оценку отражают следующие эмоциональные пометы: ирон., презр., пренебр., унижит., вульг., бран., фам., сарк. (см.: Котцова 2002: 19).

\section{Классификация и анализ лексики}

Возвращаясь к идее концептов, стоит заметить, что каждый человек является носителем индивидуального сознания, в котором возникают различные концепты. Из всего количества существующих концептов особое внимание следует обратить на концепты, описывающие субъект для самого субъекта. Они образуют так называемую систему Я-концееттов, которые имеют отношение «к данному человеку в контексте человеческого вообще» (Сапогова 2004: 50-79). Как пишут авторы статьи «Анализ Я-концептов и Я-метафор в содержании индивидуальных нарративов субъекта»,

(...) индивидуальные Я-концепты описывают субъекту его самого не только для других - в терминах, усвоенных им из культуры для фиксации общих представлений о себе, но в большей степени для самого себя - в понятиях и образах, фиксирующих его подлинное «Я», часто не предназначенное для экстериоризации и существующее только «для внутреннего пользования» (Сапогова 2004: 51).

По нашему мнению, концепт Я-ЖЕНЩИНА имеет непосредственное отношение к понятию Я-концепт, с которым связано понятие языковая личность, введённое в научный оборот Ю. Н. Карауловым, и которое представляет собой «совокупность способностей и характеристик человека, обуславливающих создание и восприятие им речевых произведений (текстов)» (Караулов 1987: 70-71).

С языковой личностью, в свою очередь, связано понятие художественный образ - т.е. любое явление, творчески воссозданное автором в художественном произведении. Художественный образ отражает действительность, т.к. при помощи своей фантазии автор преобразует существующий материал: стилистическими приёмами создает неповторимый образ, картину человеческой жизни (см.: Кононенко 2003).

Несомненно, речь, то есть так называемые нарративы (см.: Сапогова 2004: 51) героя художественного произведения влияют на структуру и содержание художественного образа. Значит, необходимо систематизировать всю совокупность текстов данного лица таким образом, чтобы они 
могли составить достаточно целостную характеристику героя как индивидуальной языковой личности. В связи с этим, в нашей работе мы обращаемся к языковой личности главной героини автобиографического романа М. Apбатовой. Героиня, по нашему мнению, в огромной мере является alter ego самой писательницы. Мы уверены, что в данном случае концепт Я-ЖЕНЩИНА можно прокомментировать, ссылаясь на мнение специалистов:

Обобщение многократно повторяющейся совокупности «Я-настоящих», актуализирующихся в ситуациях общения, деятельности и т.д., и сопоставление их с оценками и мнениями извне позволяет субъекту отстраивать уровень «Я-реального» как совокупности развивающихся представлений о себе - это наиболее устойчивый продукт социализации (его составляют известные концепты типа «Я-мужчина/женщина», «Я-взрослый/ребёнок», «Я-мать», «Я-жена», «Я-профессионал», «Я-честный», «Я-умный», «Я-счастливый» и т.п.) (см.: Сапогова 2004: 51).

Выборку исследовательского материала мы провели, опираясь на собственную языковую компетенцию, а также данные словарей (напр., Ожегов, Шведова 2009; Жуков 2010). Например, во фрагменте произведения Арбатовой: «(...) возненавидела сад, в котором так славно валяться под яблоней» нас заинтересовало слово валяться. Второе лексическое значение слова валяться - 'лежать, небрежно раскинувшись, бездельничая. Валяться на диване' (Ожегов, Шведова 2009: 68). Вместо формулировки „так славно лежать под яблоней, ничего не делая" писательница использовала более сниженное стилистически слово. Стилистические квалификаторы, которые можно при этом использовать - «разговорное» (т.е. разг.), «пренебрежительное» (т.е. пренебр.). Из вышеупомянутого произведения мы провели выборку лексических единиц (отдельных лексем и - реже - коллокаций), имеющих именно сниженную, негативную, ярко выраженную, экспрессивную, а также вульгарную окраску из всего анализируемого произведения. Это помогло нам выделить своего рода «отрицательную область» концепта Я-ЖЕНЩИНА. Конечно, невозможно было не учесть и сам контекст, который во многом определил отношение исследуемого слова или словосочетания к тому или иному типу лексики.

После выделения лексики мы приступили кеё классификации. По нашему мнению, выделенную нами стилистически сниженную лексику, связанную с иироко понимаемой темой „женщина”, следовало распределить по нескольким категориям, внутри которых образовались более узкие лексико-тематические группь (далее: ЛТГ):

Тематические группы объединяют слова, а точнее обозначаемые ими понятия, связанные с общей темой, соотносимые с одним кусочком действительности, или с фрагментом языковой картины мира. В значениях этих слов можно вы- 
делить общий смысловой признак, или семантему, на основе которого данные слова разных частей речи объединяются в одну тематическую группу (Котцова 2002: 88).

Как уже было сказано, данная лексика связана непосредственно с отношением героини, от лица которой ведётся повествование к себе самой, напр.: «я выпорхнула», «я мяукнула» и т. д. В ходе более углубленного изучения интересующей нас лексики, мы сочли необходимым разбить её на несколько более узких ЛТГ (в процессе классификации лексики по ЛТГ мы пользовались «Русским семантическим словарём» - см. Шведова 2009). В результате мы выделили 5 ЛТГ, которыми являются:

ЛТГ 1: ПЕРЕДВИЖЕНИЕ В ПРОСТРАНСТВЕ (напр.: я поползЛа на каталку);

ЛТГ 2: МЕНТАЛЬНЫЕ ДЕЙСТВИЯ (напр.: я кидалась на людей);

ЛТГ 3: ФИЗИЧЕСКИЕ ДЕЙСТВИЯ (напр.: отпихиваю от своего лица);

ЛТГ 4: ПСИХОФИЗИОЛОГИЧЕСКИЕ ДЕЙСТВИЯ (напр.: заснула и выключилась);

ЛТГ 5: ВЕРБАЛЬНЫЕ ДЕЙСТВИЯ (напр.: рыкнула я).

В ходе работы с лексикой мы пытались привести стилистические эквиваленты лексических единицы польского языка, опираясь но собственную языковую компетенцию, так как изучаемый роман не был переведён на польский язык. Также мы использовали ряд словарей (Ожегов, Шведова 2009 - «Толковый словарь русского языка»; Жуков 2010 - «Лексико-фразеологический словарь русского языка»).

Некоторые слова и обороты, характерные для стиля писательницы, мы нашли в переводе на польский язык другого автобиографического романа М. Арбатовой «Мне 46» ${ }^{1}$, изданном в Польше (пример: хихикнула переведено с соблюдением стилистической окраски - zachichotatam).

Первое, на что следует обратить внимание - это то, что все рассматриваемые лексические единицы являются глаголами, т.е. словами, выражающими процессуальность. В ходе эксцерпции объектов исследования мы встретились с несколькими лексическими единицами, относящимися к иным (чем глагол) частям речи, но таких слов было всего несколько. В связи с этим, в своих рассуждениях мы остановились на более подробном рассмотрении именно глаголов, глагольных форм и - частично - глагольных словосочетаний.

Не все лексические единицы, выделенные нами, имели соответствующие пометы-квалификаторы в словаре (прост., разг.) В некоторых случаях они вообще отсутствовали. Несмотря на это, в интересующих нас контекстах лексические единицы были отнесены именно к сниженному разговорному стилю.

M. Arbatowa 2005, Na imię mi kobieta, tłum. Teresa Kiełb, Warszawa. 
В нескольких случаях нам не удалось найти в словаре искомого значения нужного слова (например, я завалила - в значении: 'пришла'; я отрубилась - в значении: 'заснула'; я врубилась в дело - в значении: 'углубилась в тему'). Кроме «Толкового словаря русского языка», мы обращались за помощью к «Лексикофразеологическому словарю русского языка»- в случае таких фразеологических единиц, как: разуть (её) глаза, [хоть] волком вой, [быть] на последнем пределе, (носилась) как дурак с писаной торбой и т.п.)

Среди выделенных нами лексических единиц есть несколько таких, которые относятся к книжному и возвышенному стилю (на это указывают соответствующие пометы в словарях). Несмотря на это, мы всё же отнесли их к числу стилистически сниженных оборотов, поскольку в интересующем нас контексте они были использованы с иронией (ваяю, вещала).

Среди отобранных нами лексических единиц мы выделили авторский неологизм, выраженный словом обрыхлилась - в значении 'приобрела опыт'. Мы отнесли данное слово к числу стилистически сниженных в том числе изза сходства его морфемного строения с такими словами как: обзавидовалась, открестилась, которые можно причислить к стилистически сниженным.

Следующим пунктом, на который следует обратить внимание, является использование интересующих нас лексических единиц в переносном значении, например, натыкаюсь (на) = встретить (кого); потрясало (кого) = сильно удивляло (кого).

Итак, рассмотрим более подробно каждую ЛТГ в виде статей. После рассмотрения ЛТГ читателю предложена диаграмма, представляющая статистические данные, связанные с процентным отношением стилистических квалификаторов. В данной статье приводим лишь по пять статей для каждой ЛТГ. Всего при анализе было задействовано около ста примеров использования сниженной лексики и фразеологизмов.

При анализе отдельных объектов, мы опираемся на следующую схему:

\section{ЛТГ номер: название ЛТГ}

\section{контекст с анализируемой лексемой/коллокацией}

а) объяснение в свободной форме; нейтральный синоним;

б) значение слова в словаре;

в) стилистический квалификатор;

г) предлагаемый нами перевод на польский язык, то есть технически говоря, эквивалент на польском языке. Приводится также вариант эквивалента и вариант перевода контекста.

\section{ЛТГ 1: ПЕРЕДВИЖЕНИЕ В ПРОСТРАНСТВЕ}

\section{я выпорхнула из операционной, сияя}

а) я быстро вышла из операционной, с облегчением,

б) выпорхнуть - вылететь, порхнув. Птица выпорхнула из клетки (Ожегов, Шведова 2009: 117),

в) разг.,

г) wyleciałam lekko jak motyl/trzepocząc skrzydłami niczym motyl/wyfrunęłam; 
я поползла на каталку

а) медленно, с трудом отправилась по направлению,

б) поползти - начать ползти. Поползли муравьи (Ожегов, Шведова 2009: 562),

в) ирон.,

г) przeczołgałam się na wózek inwalidzki;

как последняя дура, я засеменила к часам

а) быстро зашагала,

б) семенить - идти частыми мелкими шагами (Ожегов, Шведова 2009: 710),

в) шутл.,

г) jak ostatnia idiotka drepczę ku ścianie, na której zawieszony jest zegar/jak ostatnia idiotka przebieram nogami, kierując się do ściany z zegarem;

когда я завалила в Союз писателей

а) пришла, явилась,

б) завалить/завалиться - нет искомого значения (Ожегов, Шведова 2009: 198),

в) пренебр., груб.,

г) zjawiłam się do siedziby Związku Pisarzy;

смываюсь в спальню

а) ухожу,

б) смыться - 2. уйти откуда-н, исчезнуть (обычно тайком, незаметно). Смыться

с урока (Ожегов, Шведова 2009: 737),

в) прост.,

г) ulotniłam się/wyślizguję się do sypialni.

ЛТГ 2: МЕНТАЛЬНЫЕ ДЕЙСТВИЯ

леплю очередной текст

а) составляю, придумываю,

в) пренебр.,

г) modeluję kolejny tekst/nadaję kształt kolejnemu tekstowi;

я начинаю ваять свой сюжет

а) создавать,

в) высок., ирон.,

г) piszę swój własny scenariusz;

но я не секу этого

а) не понимаю,

б) сечь - понимать, разуметь. Сечёшь? (Ожегов, Шведова 2009: 715),

в) разг., пренебр.,

г) nie łapię tego/nie czaję tego;

и тут я врубаюсь, что делать

а) вдруг я понимаю, что нужно делать,

в) груб.,

г) nagle kapuję, co trzeba robić/naglę mnie oświeciło;

я обрыхлилась, как говорили мои дети о подросшей кошке

a) неологизм: стать опытнее;

в) разг.

ЛТГ 3: ФИЗИЧЕСКИЕ ДЕЙСТВИЯ

я вылавливаю в сумке банку шпрот 

а) достаю из сумки,
б) выловить - ловя, добывать, извлечь. Выловить много рыбы (Ожегов, Шведова 2009: 114),
в) разг.,
г) wyławiam z torebki konserwę;

\section{и я впихиваю ему в руки}
а) кладу ему в руки/даю в руки/втискиваю,
б) впихнуть - втолкнуть, всунуть (Ожегов, Шведова 2009: 101),
в) прост., груб.,
г) wpycham mu do ręki/ładuję mu do ręki;

я возненавидела сад, в котором так славно валяться под яблоней

а) так славно лежать под яблоней, ничего не делая,

б) валяться - 2. лежать, небрежно раскинувшись, бездельничая. Валяться на диване (Ожегов, Шведова 2009: 68),

в) разг., пренебр.,

г) wylegiwać się;

я долго раскрашиваю физиономию
а) крашу лицо,
б) раскрасить - расписать разными красками (Ожегов, Шведова 2009: 658),
в) неодобр., ирон.,
г) nakładam/robię tapetę;

напяливаю обтягивающий комбинезон
а) одеваю,
б) напялить - 2. с трудом натянуть, надеть (узкое, тесное). 3. надеть что-н. безвкусное, неподходящее (там же: 390),
в) прост., неодобр.,
г) wciągam na siebie obcisły kombinezon/odpierniczyłam się zakładając obcisła kieckę.

\section{ЛТГ 4: ПСИХОФИЗИОЛОГИЧЕСКОЕ СОСТОЯНИЕ я снова отрубилась}
а) заснула,
в) груб.,
г) znów uderzyłam w kimono/zachrapałam;

я утром свалилась

а) уснула от усталости,

б) свалиться - в значении валиться - падать. Переносное значение (Ожегов, Шведова 2009: 699),

в) пренебр.,

г) nad ranem mnie zmuliło;

заснула и выключилась

а) заснула, отключив сознание,

б) выключиться - 2. исчезнуть, устраниться. Перестать принимать участие

(Ожегов, Шведова 2009: 113),

в) прост.,

г) zapadłam w sen zimowy/odpłynęłam; 
шмыгаю носом

а) всхлипываю от плача,

б) шмыгать - делать носом втягивающие движения, хлюпать (Ожегов, Шведова 2009: 899),

в) разг.,

г) chlipnęłam;

я зацепила ушами диалог Ирины Васильевны

а) нечаянно услышала/диалог донёсся,

в) груб.,

г) chwyciłam uchem/złowiłam uchem.

ЛТГ 5: ВЕРБАЛЬНЫЕ ДЕЙСТВИЯ

оборав шестерок в гражданском, я обнаруживаю старшего

а) очень строго, с негодованием, повысив голос разговаривая,

в) груб.,

г) po rzucaniu mięsem/po obrzuceniu epitetami;

я извожу мужа нытьем

а) мучаю,

б) извести - 3. то же, что измучить (Ожегов, Шведова 2009: 238),

в) разг., неодобр.,

г) zadręczam/nurtuję męża biadoleniem/truję mężowi tyłek;

хихикнула я

а) сказала с иронической улыбкой,

б) хихикать - смеяться тихо или исподтишка, со злорадством (Ожегов, Шведова 2009: 862),

в) разг., шутл.,

г) zachichotałam/zarechotałam;

замурлыкала я

а) ласково, тихим певучим голосом,

б) мурлыкать - 2. тихонько напевать (Ожегов, Шведова 2009: 370),

в) разг.,

г) zamruczałam;

зашипела я

а) злобно проговорила/ сквозь зубы,

б) шипеть - 2. говорить сдавленным от злости голосом (Ожегов, Шведова 2009: 896),

в) разг., неодобр.,

г) zasyczałam/syknęłam.

Процентное соотношение помет-квалификаторов, использованных в работе: 


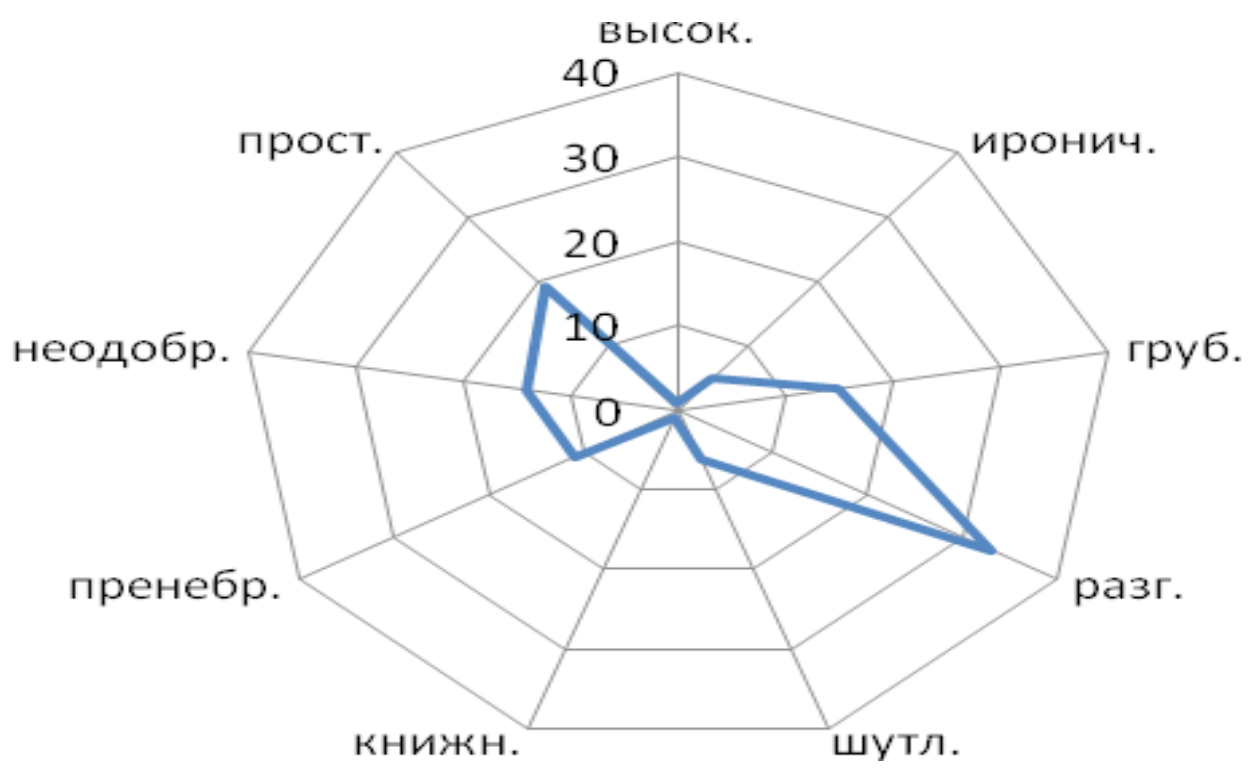

Диаграмма 1. Все встречающиеся квалификаторы.

\section{КонцеПт Я-ЖЕНЩИНА. ВЫводЫ}

Проанализировав интересующую нас лексику, распределённую по нескольким ЛТГ, мы приступим к общему описанию концепта, сделаем соответствующие выводы, а также подведём итоги.

Рассматривая систему построения интересующего нас концепта, мы заметили одну любопытную тенденцию. Мы имеем в виду то, что можно выделить и разграничить внутри концепта Я-ЖЕНЩИНА две области: 1) касающаяся животного мира и 2) область, касающаяся мира людей.

1) Область, касающаяся животного мира. В данном случае представляется возможным проследить тенденцию Марии Арбатовой использовать в качестве наименования собственных действий глаголы, относящиеся к действиям животных. Как пример можно привести следующие слова: выпорхнула, выползаю, поползла, влетела, выть волком, рыкнула, замурлыкала, зашипела. Писательница сравнивает свои действия с действиями животных (выпорхнуть легко, как бабочка; выползать, как змея). Вопрос о переносном значении и моделях метафоризации в нашей работе мы не затрагивали.

2) Область, касающаяся мира людей - действия, свойственные человеку. Можно с большой долей уверенности утверждать, что отрицательная, лексически сниженная, спейоративизированная сторона концепта Я-ЖЕНЩИНА, выстраиваемого на материале романа М. Арбатовой, создаётся по нескольким принципам. В своих высказываниях героиня романа, от лица которой 
ведётся повествование: 1) указывает на неловкость/неуклюжесть в своих действиях (протискиваюсь; карабкаюсь; слоняюсь; как бы не свалиться; натыкаюсь); 2) указывает на бессмысленность собственных действий (носилась, как дурак); 3) указывает на собственную слабость, сравнивает свои действия с действиями ребёнка, проявляет смешливое отношение с собственной персоне (засеменила; промямлила; поплакалась; ною; завопила); 4) указывает на неуверенность в правильности своих дальнейших действий/в последствиях действий (слоняюсь); 5) указывает на замедленное мышление (я не врубаюсь; не секу; прежде чем я соображаю); 6) указывает на пренебрежительное отношение к себе (запихиваться, завалила; смываюсь; полезла; как бы не свалиться); 7) показывает негативное/хамоватое отношение к другим (отшивать, отнимаю, сунула (ему), запихиваю, тошнит от); 8) показывает небрежное отношение к предметам (захлопнула дверь); 9) показывает небрежное отношение к собственному внешнему виду (раскрашиваю физиономию; напяливаю на себя); 10) указывает на преступные действия/непристойные действия (врезать (кому); отсиживаться (где-то); стоять на стрёме); 11) показывает собственное негативное влияние на людей, отдавая себе отчёт в этом (извожу мужа); 12) указывает на совершение торопливых действий (несусь; влетела (опоздав); 13) указывает на использование непристойных выражений (оборав, посылаю многоэтажным матом; конструктивно матерюсь); 14) указывает на склонность к состоянию нервного возбуждения (оборала); 15) указывает на присутствие чувства стыда (давлюсь салатом; ёжусь от стыда).

Интересующий нас концепт Я-ЖЕНЩИНА скрывает за собой сгусток информации. Содержание отрицательной стороны концепта отражает наличие у главной героини слабостей, нечуждых любому человеку, указывает на многие недостатки объекта, некую небрежность по отношению к себе. Однако следует отметить, что о себе, как о женщине, героиня говорит без высокомерия, имеет адекватный взгляд на происходящее вокруг.

Довольно отчётливо прослеживается мысль о том, что «Я» не превозносится на пьедестал, отношение объекта к себе самому разумное, не высокопарное, скорее наоборот: подчёркивающее способность оставаться Человеком даже со слабостями. Этот глобальный, то есть используемый на протяжении всего романа, приём можно назвать «сакрализацией через пейоративизацию».

Всё это позволяет сделать вывод о том, что концепт Я-ЖЕНЩИНА, выстраиваемый на материале текста Арбатовой, отражает не только пренебрежение к себе, грубость, неодобрение, наличие самоиронии, некую фамильярность по отношению к самой себе. Анализированные стилистические приёмы указывают на некий - пусть бытовой - реализм действий героини. Тем самым, главный персонаж становится для нас похожим на нас самих. Героиня честна по отношению к самой себе, а писательница - по отношению к читателю. Возможно, это и создает эффект психологической разгрузки при чтении произведений Марии Арбатовой. 
Содержание концепта имеет неоднородный и противоречивый характер. Так как нами была рассмотрена только одна его сторона - сниженная на уровне стилистики, мы не можем отрицать наличие и другой - «возвышенной» стороны. Однако для полной уверенности необходимо будет в дальнейшем проанализировать оставшуюся без анализа лексику, связанную с темой женщины.

Описывая главную героиню, Мария Арбатова создала собирательный образ советской женщины, живущей в тяжелые времена на закате советской эпохи, когда требовались огромные силы и умение принимать мир таким, какой он есть. Подобные испытания выпали на долю многих советских женщин, у каждой из них своя неповторимая история. Несомненно, в творчестве современных писательниц есть много общих тем, макро- и микротематических мотивов, именно поэтому изучение данного концепта представляет собой научный интерес. Стоит также выяснить, напоминает ли портрет женщины в творчестве российских писательниц портреты героинь той же эпохи в польской литературе. В связи с этим, в следующих исследованиях мы намерены изучить и представить сравнение концепта ЖЕНЩИНА в творчестве польской писательницы Катажины Грохоли и упомянутой в настоящей статье Марии Арбатовой.

\section{Библиография}

Адамова В. С. (2011), Художественный кониепт как единииа творческого процесса в литературоведческом осмыслении, Материалы ХVIII Международной конференции студентов, аспирантов и молодых ученых «Ломоносов». Секиия «Филология», Москва, с. 654. Арбатова, М. (2008), Меня зовут женщина, Москва.

Arbatowa M. (2005), Na imię mi kobieta, tłum. Teresa Kiełb, Warszawa.

Гачев Г. Д. (1972), Жизнь художественного сознания, Москва.

Дзюба Е. В. (2011), Концепт «ум» в русской лингвокультуре, Екатеринбург, с. 3.

Жеребило Т. В. (2010), Словарь лингвистических терминов, изд. 5-е, испр-е и дополненное, Назрань, с. 84.

Жуков А. В. (2010), Лексико-фразеологический словарь русского языка, Москва.

Зусман В. Г. (2001), Диалог и кониепт в литературе. Литература и музыка, Нижний Новгород.

Карасик В. И. (2004), Языковой круг: личность, концепты, дискурс, Москва.

Караулов Ю. Н. (1987), Русский язык и языковая личность, Москва, с. 70-71.

Кононенко Б. И. (2003), Большой толковый словарь по культурологии, Москва.

Котцова Е. Е. (2002), Лексическая семантика в системно-тематическом аспекте, Архангельск, c. 19, c. 88 .

Лихачев Д. С. (1997), Концептосфера русского языка, [в:] Русская словесность. От теории словесности к структуре текста. Антология, Москва, с. 17.

Маслова В. А. (2007), Когнитивная лингвистика, Москва, с. 24.

Миллер Л. В. (2000), Художественный кониепт как смысловая и эстетическая категория // Мир русского слова, № 4, Санкт-Петербург, с. 39-45. 
Mirowicz A., Dulewiczowa I., Grek-Pabisowa I. (1987), Wielki stownik rosyjsko-polski, Moskwa, т. 1, 2. Warszawa.

Сапогова Е. Е. (2004), Анализ Я-концептов и Я-метафор в содержании индивидуальных нарративов субъекта, [в:] Прикладная психология: достижения и перспективы, ред. Л. А. Мирская, Т. Ю. Синченко, В. Г.Ромека, Ростов-на-Дону, с. 50-79.

Попова З. Д., Стернин И. А. (2007), Когнитивная лингвистика, Москва, с. 315.

Ожегов С. И., Шведова Н. Ю. (2009), Толковый словарь русского языка, Москва.

Шведова Н. Ю. (1998), Русский семантический словарь. Толковый словарь, систематизированный по классам слов и значений, т. 3, Москва.

\title{
Anastasia Oshchepkova
}

\section{Concept of «I am a WOMAN»: colloquialisms in Maria Arbatova's novel «My name is the woman»}

\begin{abstract}
Summary
This article relates to the field of cultural linguistics, and also touches upon the area of cognitive linguistics. The purpose is to describe the concept of «I am a WOMAN» by analyzing vocabulary highlighted in the text, which relates to a reduced style and which is distributed into lexical-thematic groups. In addition, this article provides equivalents of lexical units of central focus in Polish.

The paper consists of three parts. The first is the theoretical part, which provides an overview of the problem. It is given in order to familiarize the reader with the following terminology: a concept, an art concept, stylistically reduced vocabulary. Next follows the practical part of the article, which includes the description of each of the selected lexical and thematic groups. Vocabulary is analyzed and Polish equivalents offered. In the third and final part, the concept of «I am a WOMAN» is described, basic conclusions made, as well as the difficulties and peculiarities of translation are discussed.
\end{abstract}

